\title{
Driving Ability in Alzheimer Disease Spectrum: Neural Basis, Assessment, and Potential Use of Optic Flow Event-Related Potentials
}

\author{
Takao Yamasaki ${ }^{1,2 *}$ and Shozo Tobimatsu ${ }^{1}$ \\ ${ }^{1}$ Department of Clinical Neurophysiology, Neurological Institute, Graduate School of Medical Sciences, Kyushu University, \\ Fukuoka, Japan, ${ }^{2}$ Department of Neurology, Minkodo Minohara Hospital, Fukuoka, Japan
}

Driving requires multiple cognitive functions including visuospatial perception and recruits widespread brain networks. Recently, traffic accidents in dementia, particularly in Alzheimer disease spectrum (ADS), have increased and become an urgent social problem. Therefore, it is necessary to develop the objective and reliable biomarkers for driving ability in patients with ADS. Interestingly, even in the early stage of the disease, patients with ADS are characterized by the impairment of visuospatial function such as radial optic flow (OF) perception related to self-motion perception. For the last decade,

OPEN ACCESS

Edited by:

Pravat K. Mandal,

National Brain Research Centre (NBRC), India

Reviewed by:

Deepika Shukla,

National Brain Research Centre

(NBRC), India

Jordi A. Matias-Guiu,

Hospital Clínico San Carlos, Spain

*Correspondence: Takao Yamasak yamasa@neurophy.med.kyushu-u.ac.jp

Specialty section:

This article was submitted to Applied Neuroimaging, a section of the journal Frontiers in Neurology

Received: 01 June 2018 Accepted: 17 August 2018 Published: 07 September 2018

Citation: Yamasaki T and Tobimatsu S (2018) Driving Ability in Alzheimer Disease Spectrum: Neural Basis, Assessment, and Potential Use of Optic Flow

Event-Related Potentials.

Front. Neurol. 9:750

doi: 10.3389/fneur.2018.00750 we have studied the feasibility of event-related potentials (ERPs) in response to radial OF in ADS and proposed that OF-ERPs provided an additional information on the alteration of visuospatial perception in ADS (1, 2). Hence, we hypothesized that OF-ERPs can be a possible predictive biomarker of driving ability in ADS. In this review, the recent concept of neural substrates of driving in healthy humans are firstly outlined. Second, we mention the alterations of driving performance and its brain network in ADS. Third, the current status of assessment tools for driving ability is stated. Fourth, we describe ERP studies related to driving ability in ADS. Further, the neural basis of OF processing and OF-ERPs in healthy humans are mentioned. Finally, the application of OF-ERPs to ADS is described. The aim of this review was to introduce the potential use of OF-ERPs for assessment of driving ability in ADS.

Keywords: Alzheimer disease spectrum, radial optic flow perception, event-related potentials, driving ability, Alzheimer's disease, mild cognitive impairment

\section{INTRODUCTION}

Driving is a complicated skill that needs to integrate multiple cognitive, perceptual and motor abilities (3), and is supported by widely distributed brain network responsible for these complex processes (4-8). The driving ability can be disturbed by a decline in these brain networks due to normal aging and cognitive impairment such as dementia $(3,9-11)$. In recent years, the number of individuals with dementia is steadily increasing due to aging of the population (12). Under such circumstances, traffic accidents in individuals with dementia have increased and become an urgent social problem (11).

Among dementia, Alzheimer's disease (AD) is the most common (12). AD progresses on a spectrum with three stages, so-called, "AD spectrum (ADS)" (13); (1) preclinical AD (14), (2) mild cognitive impairment (MCI) due to $\mathrm{AD}$ (15), and (3) AD dementia (16). AD dementia is 
characterized by the impairment of short-term episodic memory, orientation, visuospatial function, language and executive function (12). The major neuropathological hallmarks of $\mathrm{AD}$ are deposition of $\beta$ amyloid (senile plaques) and accumulation of neurofibrillary tangles, which cause a series of toxic events that result in synaptic dysfunction, neuronal loss and brain atrophy (12). Overall, multiple cognitive function associated with distributed brain network are impaired due to the AD pathology, resulting in the decline of driving ability in patients with $\mathrm{AD}$.

There are various methods to assess driving ability, which include on-road test, driving simulation, and neuropsychological tests. However, recent systematic review and meta-analysis on these methods have demonstrated a lack of consistency of the findings among the studies though the several cognitive tests are considered to be the predictors of driving performance in $\mathrm{AD}$ patients $(3,17)$. So far, there have been no tests sufficient to determine driving safety, so it is necessary to establish a reliable method that can accurately evaluate driving ability in ADS. Interestingly, visuospatial dysfunction is often an early symptom even in the early stage of ADS $(18,19)$. Specifically, psychophysical studies demonstrated that AD patients exhibited selective elevation of motion coherence thresholds for radial optic flow (OF) motion which was related to self-motion perception (20), compared with those of coherent horizontal (HO) motion and static forms (19). In addition, the impaired OF perception was correlated with poor performance of the spatial navigation test (19). These findings suggest that the deficits of OF perception is responsible for the impairment of spatial navigation including the driving performance in $\mathrm{AD}$ patients. Some patients with MCI also exhibited selective impairment of coherent $\mathrm{OF}$ motion perception (18).

Event-rerated potentials (ERPs) are a pertinent tool to assess the visual function as well as dysfunction in humans because ERPs are non-invasive, objective, rapid, repeatable with the low cost. ERPs are also characterized by excellent temporal resolution $(<1 \mathrm{~ms})$ and can measure neural activity directly compared with functional magnetic resonance imaging (fMRI) (21, 22). Therefore, radial OF-ERPs may be a neural biomarker for decline of driving performance in ADS.

In this review, we first outline the neural basis of driving ability in healthy humans. Second, we describe the alterations of performance and associated brain function for driving in ADS. Third, we refer to current status of the assessment tests for driving and its problems. Fourth, ERP studies related to driving ability in ADS are stated. Further, we mention the neural basis of OF perception and findings of OF-related ERPs in healthy humans. Finally, we introduce the potential use of OF-ERPs for assessing driving ability of ADS. The aim of this review was to stress the feasibility of neurophysiological evaluation of OF perception that can be a neural biomarker for altered driving ability in ADS.

\section{NEURAL BASIS OF DRIVING ABILITY IN HEALTHY INDIVIDUALS}

Driving requires the coordination of multiple cognitive functions and recruitment of associated multiple brain regions. Several fMRI studies on various driving tasks have demonstrated the activation of widespread brain network including occipital, parietal, frontal, motor and cerebellar regions and others to maintain safe driving (4-8). Figure 1 shows an example of activated brain regions while driving in a recent fMRI study (4). In their study, during driving only condition, the occipital activations were observed in the inferior, superior and middle occipital gyri and lingual gyrus. The activated areas of parietal lobe were superior and inferior parietal lobe, postcentral gyrus, and precuneus. The activations of frontal regions consisted of the inferior, middle and superior frontal gyri and precentral gyrus. The superior and middle temporal gyri were the activated areas of temporal regions. The activations of the cerebellum included the uvular, declive, and cerebellar tonsil. In addition, the limbic region such as cingulate gyrus, sub-lobar region including insula and lentiform nucleus were activated (4).

During driving, occipital and parietal regions plays a crucial role in visuospatial perception and attention to visual motion and fixed landmarks during vehicle movement. The frontal region is important for the executive function, working memory, processing thoughts, and decision-making. The motor and cerebellar regions engage in fine-control and action planning during movement execution (4-8). Furthermore, the recruitment of these brain regions is changeable but not uniform while driving. For instance, during distracted driving, brain activations shift the posterior regions to the frontal regions, particularly in the prefrontal areas (6). Taken together, because brain networks related to driving are broadly distributed, they may be susceptible to brain disorder such as ADS which shows extensive brain damage.

\section{ALTERED DRIVING PERFORMANCE IN ADS}

Older drivers are at higher risk for traffic accidents such as crashes, injuries and deaths than other age groups (11). Further, individuals with $\mathrm{AD}$ dementia have an increased risk of traffic accidents compared to healthy older drivers (11). Severity of decline in driving performance was correlated with a degree of cognitive impairment in $\mathrm{AD}$ dementia (23). Individuals with MCI also had significantly more errors (collisions, center line crossings, road edge excursions, stop sign missed, speed limit exceedance) compared with healthy control drivers (10). MCI is classified into two types: amnestic MCI (aMCI) (with memory impairment) and non-aMCI (without memory impairment) (24). MCI is further classified into single-domain MCI (with impairment in single cognitive domain) and multiple-domain MCI (with impairment in multiple cognitive domain) (24). Patients with multiple-domain aMCI have the two or more impairments of memory, attention, viusospatial function, and executive function. Comparing multiple-domain aMCI with single-domain aMCI, the former demonstrates greater driving difficulty compared with the latter and healthy controls (10). Since all these cognitive functions are important for driving performance, multiple-domain aMCI may exhibit a greater driving difficulty than single-domain aMCI.

A single-photon emission computed tomography (SPECT) study has demonstrated that severity of impaired driving 


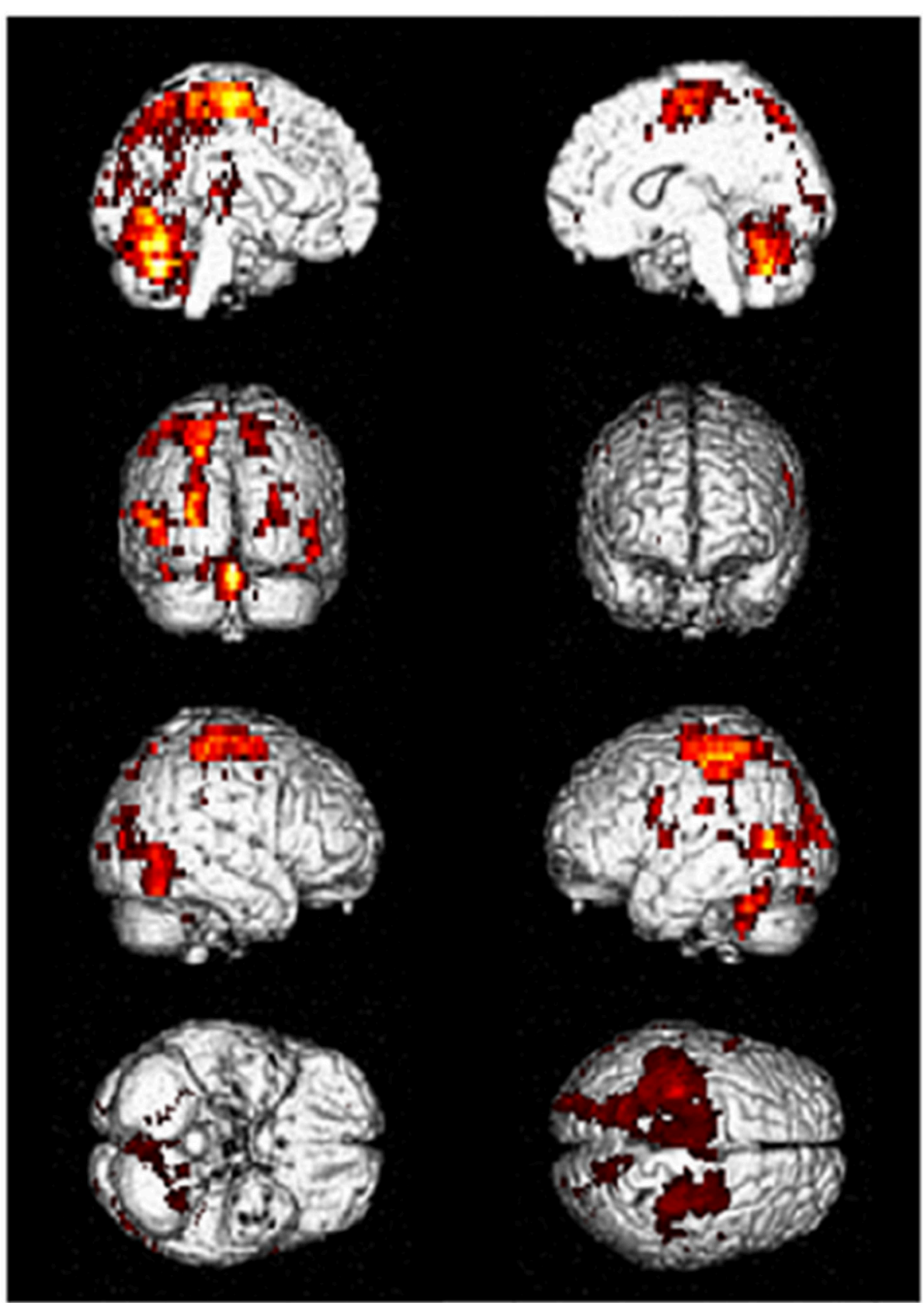

FIGURE 1 | Activated brain regions during driving in fMRI. Distributed brain networks including occipital, parietal, frontal, motor, and cerebellar regions are mainly activated while driving only task. fMRI, functional magnetic resonance imaging. [Modified from (4), licensed under Creative Commons].

performance is significantly correlated with the changes of cerebral blood flow in the temporo-parietal regions in early stage of AD (25). A positron emission tomography (PET) study showed that the executive functioning was correlated with metabolism in the temporo-parietal regions, which was impaired in early stage of AD (26). Neuropsychological studies also reported a significant relationship between driving performance and visuospatial perceptual ability in $\mathrm{AD}$ (17). These findings indicate that the hypoperfusion or hypometabolism of temporoparietal regions reflects the impairments of visuospatial perception and executive function, which result in impaired driving performance in early stage of $\mathrm{AD}$. Moreover, with increased severity of driving impairment, the perfusion of frontal region was also reduced in addition to temporo-parietal regions in SPECT (25). The AD pathology is observed in the temporo-parietal regions in the early stage of the disease while 
that pathology spread into the frontal regions in the later stage (27). Therefore, the impairment of executive function involving the frontal regions can be more correlated with the driving impairment for the late stage of $\mathrm{AD}$. Interestingly, a recent PET study have revealed that driving risk is strongly correlated with accumulation of amyloid even in the preclinical stage of $\mathrm{AD}$ (28). In another study using tau and amyloid PET, participants at Stage 2 [amyloid $(+)$ and tau $(+)$ ] of preclinical AD (14) were more likely to receive a marginal/fail rating compared to participants at Stage 0 [amyloid (-) and tau (-)] or 1 [amyloid (+) and tau (-)] $(11,14)$. This finding suggests that individuals with preclinical $\mathrm{AD}$ (Stage 2) may already decline in driving skills.

Overall, the driving performance is gradually worsening along with the course of ADS from preclinical $\mathrm{AD}$ to $\mathrm{AD}$ dementia. These alterations of driving performance seem to be induced by the progression of $\mathrm{AD}$ pathology. In particular, the early pathological change in the posterior temporo-parietal regions associated with visuospatial function (OF perception) may be responsible for the impaired driving in the early stage of ADS.

\section{ASSESSMENT TOOLS FOR DRIVING ABILITY IN ADS}

Various methods including on-road test, driving simulation and neuropsychological tests have been used for evaluating driving ability $(3,17,29)$. The on-road test is the gold standard for assessing fitness to drive, but it requires much time for patients. There is also a need for someone who is proficient in the judgment. The driving simulation is similar to the on-road test, but it is expensive. Therefore, these two tests cannot be routinely performed at the medical clinics. For this reason, neuropsychological tests are commonly used. Neuropsychological tests can evaluate various aspects of brain function including attention, executive function and visuospatial abilities known to be impaired in patients with ADS. For example, the following tests are frequently used; the MiniMental State Examination (MMSE) for memory, attention and language skill, the Trail Making Test Part A and B (TMT-A and -B) for cognitive flexibility, Drawing test for visuo-constructive ability, and Maze test for visual orientation (29). However, these neuropsychological examinations, especially when doing multiple tests, require a long time to perform, so that patients often get tired. Characteristics with some pros and cons of these assessment tools are briefly summarized in Table $\mathbf{1 .}$

There have been many studies that investigate the usefulness of above mentioned tests as predictors of driving ability (3, 17, 29). However, a recent systematic review (17) demonstrated a lack of consistency in the findings, with some studies showing a relationship between cognitive test and driving performance for individuals with $\mathrm{AD}$, whereas others did not. Further, this review suggested that deficits in a single cognitive ability were not a reliable predictor of driving performance. In contrast, a composite battery that assessed the multiple cognitive domains required to be an efficient driver was the best predictor of driving performance in individuals with $\mathrm{AD}$ (17). Another study compared the predictive value of the three types of assessment such as clinical interview, neuropsychological test battery (including multiple tests) and driving simulation (29). They found that neuropsychological assessment provided the best prediction of fitness to drive. Clinical interviews were less objective and less standardized than neuropsychological

TABLE 1 | Assessment tools for driving ability in ADS.

\begin{tabular}{|c|c|c|c|}
\hline Assessment tools & Characteristics & Pros & Cons \\
\hline On-road test & $\begin{array}{l}\text { - Gold standard } \\
\text { - Evaluate driving abilities using actual vehicle } \\
\text { by a trained expert }\end{array}$ & - Close to driving in the natural environment & $\begin{array}{l}\text { - Expensive } \\
\text { - Limited availability } \\
\text { - Need a trained expert } \\
\text { - Long time to perform } \\
\text { - Cannot examine the } \\
\text { driving ability under } \\
\text { hazardous conditions }\end{array}$ \\
\hline Driving simulators & $\begin{array}{l}\text { - Mimic real-world driving using a front monitor, } \\
\text { a handle, an accelerator, a brake pedal, etc. } \\
\text { which resemble an actual vehicle }\end{array}$ & $\begin{array}{l}\text { - Wide range of test conditions (e.g., night and day, } \\
\text { different weather conditions, or road } \\
\text { environments) } \\
\text { - Especially, we can safely examine the driving } \\
\text { performance under hazardous conditions }\end{array}$ & $\begin{array}{l}\text { - Expensive } \\
\text { - Limited availability }\end{array}$ \\
\hline $\begin{array}{l}\text { Neuropsychological } \\
\text { tests }\end{array}$ & $\begin{array}{l}\text { - Assess various cognitive functions } \\
\text { indispensable for driving (e.g., attention, } \\
\text { executive function and visuospatial abilities, } \\
\text { etc) }\end{array}$ & $\begin{array}{l}\text { - Widely available } \\
\text { - Multiple options for standardized measures }\end{array}$ & $\begin{array}{l}\text { - Long time to perform } \\
\text { - Need a trained expert }\end{array}$ \\
\hline ERPs & $\begin{array}{l}\text { - Directly measure neural activity from scalp } \\
\text { electrodes while watching OF stimuli in the } \\
\text { case of OF-ERPs }\end{array}$ & $\begin{array}{l}\text { - Widely available } \\
\text { - Non-invasive } \\
\text { - Inexpensive } \\
\text { - Short time to perform } \\
\text { - Easy to use }\end{array}$ & $\begin{array}{l}\text { - Currently not } \\
\text { standardization for } \\
\text { driving assessment }\end{array}$ \\
\hline
\end{tabular}

ERPs, event-related potentials; OF, optic flow. 
tests and driving simulation. Driving simulation is also not sufficiently predictive if used alone. However, combining all three types of assessments yielded the best prediction for fitness to drive in patients with $\mathrm{AD}$ (29). Other systematic review and meta-analysis have demonstrated that executive function, attention, visuospatial function and global cognition revealed by neuropsychological tests may be predictive of driving performance in patients with MCI and AD. Specifically, TMT$\mathrm{A}$ and $-\mathrm{B}$ and Maze test emerged as the best single predictors of driving performance though there were variability and inconsistencies. On-road and simulator assessments have yielded inconsistent results in terms of the safety to drive in patients with MCI and $\mathrm{AD}(3)$.

From the results of these studies, there has been no single test sufficient to determine driving safety in patients with MCI and $\mathrm{AD}$ though the combined use of these tests is somewhat useful. Accordingly, it is necessary to establish an objective method that can be performed easily, in a short time, at a low cost, but has high reliability. Note that ERPs have all such features, therefore, ERPs are suitable for evaluating driving ability in ADS. In the following section, we describe ERP researches on driving evaluation in ADS.

\section{ASSESSMENT OF DRIVING ABILITY IN ADS USING ERPS}

ERPs are electrical potential generated by the brain time-locked to a sensory, cognitive, or motor event and provide a powerful, non-invasive technique with superb temporal resolution, for studying the brain's synaptic function (30-32). In general, early ERP components $(<200 \mathrm{~ms}$ ) reflect sensory processes as they depend mainly on the physical parameters of the stimulus, socalled exogenous component. Conversely, later ERP components (> $200 \mathrm{~ms}$ ) are relatively more dependent on the mental operations performed on the stimuli as well as on non-sensory factors such as predictability, higher perceptual and semantic features, so-called endogenous component.

ERPs have been extensively used for functional evaluation of brain in ADS (30-32). The P300 component (around at 300$500 \mathrm{~ms}$ ) elicited by an oddball paradigm has been most studied in $\mathrm{ADS}$ as the convenient measure of the cognitive dysfunction. In general, early sensory components at around 50-100 ms are relatively spared whereas potentials starting around $200 \mathrm{~ms}$ and beyond are more consistently abnormal even in the early stage of $\mathrm{AD}$ and MCI. Thus, ERPs may reveal neurophysiological changes related to the expansion of the neocortical association areas of $\mathrm{AD}$ pathology (32).

For the ERP research on driving, the P300 cognitive component is often used as an index of driving performance in healthy individuals (33-36). However, there have been no P300-ERP studies on driving ability in ADS. To our knowledge, only two ERP studies used N200 component for the driving ability of $\mathrm{AD}(37,38)$ (Table 2). In a study of (37), ERPs were recorded in young and older normal controls, and early $\mathrm{AD}$ patients while participants viewed real-world videos and dot motion stimuli (OF) simulating self-movement scenes.
In both stimulus conditions, N200 latencies were delayed by aging whereas $\mathrm{AD}$ patients exhibited the diminished N200 amplitude. In addition, $\mathrm{AD}$ patients were uniquely unresponsive to increments in motion speed. Since OF is crucial for speed judgments and braking during vehicular navigation, the authors proposed that the $\mathrm{AD}$ unresponsiveness to accelerations might reveal some of the mechanism involved in their driving impairment and potentially help identify high-risk individuals at earlier stage. In another study (abstract form) (38), early $\mathrm{AD}$ patients and older normal control took a virtual reality driving evaluation that incorporates multiple cognitive, visual and motor tests. OF-ERPs were also recorded. Compared to older normal control, AD patients had significantly lower driving scores and smaller N200 amplitudes. Furthermore, there was a highly significant correlation between driving scores and N200 amplitudes. The authors concluded that significant correlations between vehicular driving scores and N200 amplitudes supported the role of extrastriate cortical dysfunction in impaired driving capacity and that the potential use of ERPs as screening tools for selective functional impairments and as biomarkers of AD.

These two studies $(37,38)$ suggest that OF-ERPs (sensory N200 component) may be useful for evaluation of driving ability in AD. However, it remains unknown whether the N200 component is the best predictor of driving ability in $\mathrm{AD}$, and whether or not OF-ERPs can be an index of driving ability even in aMCI. For the last decade, we have been studying the feasibility of sensory ERPs in response to radial OF in aMCI and $\mathrm{AD}$ and proposed that OF-ERPs provided an additional information on the alteration of visuospatial perception in ADS $(1,2)$. The visuospatial deficits (impaired OF perception) related to the posterior temporo-parietal dysfunction play a key role in the navigational or driving impairment in $\operatorname{ADS}(18,19,25)$. Hence, we hypothesized that sensory ERPs elicited by OF but not P300 cognitive ERPs could be a neural biomarker in driving impairment even in the early stage of ADS. In the following section, we describe neural basis of OF processing in healthy humans and the potential use of OF-ERPs as a driving evaluation method.

\section{NEURAL BASIS OF OF PERCEPTION IN HEALTHY HUMANS}

When we move through our environment with walking or cars, the radial pattern of $\mathrm{OF}$ is produced at the retina (Figure 2A). The ability of visual motion system that analyzes $\mathrm{OF}$ is biologically important because it provides visual cues that can be used to perceive the direction of self-motion, to guide locomotion and to avoid obstacles $(20,39)$. Thus, the drivers must analyze radial $\mathrm{OF}$ information continuously to control his/her vehicle during driving, so that the OF processing is indispensable for safe driving.

In humans, there are two functionally and anatomically segregated visual pathways: the ventral and dorsal pathways (Figure 3) (21, 22, 42). Both pathways begin in the retina and project to the primary visual cortex (V1). After V1, the ventral 
TABLE 2 | ERP studies on driving ability in ADS.

\begin{tabular}{|c|c|c|c|c|}
\hline References & Participants & Study design and protocol & Outcome measure & Summary of main findings \\
\hline $\begin{array}{l}\text { Fernandez and } \\
\text { Duffy (2012) (37) }\end{array}$ & $\begin{array}{l}\text { - }[\mathrm{OF} \text { (dot motion)] } \\
\text { - Early AD ( } n=15 \text {; age, } 78.6 \\
\text { 土8.0) } \\
\text { - Older normal control ( } n=16 \text {; } \\
\text { age, } 76.2 \pm 10.0) \\
\text { - Young normal control } \\
\text { ( } n=12 ; \text { age, unknown) } \\
\text { [Real-world video motion } \\
\text { stimuli] } \\
\text { - Early AD ( } n=6 \text {; age, } 73.2 \pm \\
\text { 6.3) } \\
\text { - Older normal control }(n=5 ; \\
\text { age, } 70.6 \pm 6.4) \\
\text { - Young normal control }(n=9 ; \\
\text { age, } 29.33 \pm 8.5)\end{array}$ & $\begin{array}{l}\text { - Cross-sectional study } \\
\text { - ERPs evoked by OF (dot } \\
\text { motion) } \\
\text { (Changes of coherence and } \\
\text { speed) } \\
\text { - ERPs evoked by real-world } \\
\text { video motion stimuli } \\
\text { (Changes of coherence and } \\
\text { speed) }\end{array}$ & - N200 amplitude and latency & $\begin{array}{l}\text { - Diminished N200 amplitude in early AD } \\
\text { - Increasing speed elicits smaller N200 } \\
\text { amplitudes in early AD }\end{array}$ \\
\hline Yamasaki et al (1) & $\begin{array}{l}\text { - aMCl }(n=18 ; \text { age, } 72.4 \pm \\
\text { 6.9) } \\
\text { - Early AD ( } n=18 \text {; age, } 75.5 \\
\quad \pm 5.7) \\
\text { - Older normal control }(n=18 \text {; } \\
\text { age, } 71.8 \pm 4.1) \\
\text { - Young normal control } \\
\text { ( } n=18 ; \text { age, } 28.2 \pm 5.1)\end{array}$ & $\begin{array}{l}\text { - Cross-sectional study } \\
\text { - ERPs evoked by OF and HO } \\
\text { (dot motion) }\end{array}$ & $\begin{array}{l}\text { - N170 and P200 amplitudes } \\
\text { and latencies }\end{array}$ & $\begin{array}{l}\text { - Prolonged latency of OF-specific P200 in } \\
\text { aMCl } \\
\text { - Prolonged latencies of N170 and P200 in } \\
\text { early AD } \\
\text { - Significant correlation between } \\
\text { OF-specific P200 latency and MMSE } \\
\text { score }\end{array}$ \\
\hline Yamasaki et al (2) & $\begin{array}{l}\text { - aMCl }(n=15 ; \text { age, } 74.4 \pm \\
\text { 4.4) } \\
\text { - Older normal control }(n=15 \text {; } \\
\text { age, } 73.5 \pm 4.5) \\
\text { - Young normal control } \\
(n=15 ; \text { age, } 27.9 \pm 5.0)\end{array}$ & $\begin{array}{l}\text { - Cross-sectional study } \\
\text { - ERPs evoked by OF (dot } \\
\text { motion), faces, words, } \\
\text { chromatic and achromatic } \\
\text { gratings }\end{array}$ & $\begin{array}{l}\text { - N170 and P200 amplitudes } \\
\text { and latencies for OF } \\
\text { - N170 amplitudes and } \\
\text { latencies for faces and words } \\
\text { - N120 amplitude and latency } \\
\text { for chromatic gratings } \\
\text { - Steady-state response for } \\
\text { achromatic gratings }\end{array}$ & $\begin{array}{l}\text { - Prolonged } \mathrm{N} 170 \text { and P200 latencies for } \\
\text { OF in aMCl } \\
\text { - Prolonged N170 latencies for faces and } \\
\text { words in } \mathrm{AMCl} \\
\text { - Normal N120 for chromatic gratings in } \\
\text { aMCl } \\
\text { - Normal steady-state response for } \\
\text { achromatic gratings in aMCl } \\
\text { - Significant correlations between N170 } \\
\text { latency for OF and LM WMS-R scores, } \\
\text { and between P200 amplitude for OF and } \\
\text { LM WMS-R scores } \\
\text { - High AUC in N170 and P200 latencies } \\
\text { for OF in ROC analysis }\end{array}$ \\
\hline
\end{tabular}

aMCI, amnestic mild cognitive impairment; AD, Alzheimer's disease; ERPS, event-related potentials; OF, optic flow; MMSE, Mini-Mental State Examination; LM WMS-R, Iogical memory in Wechsler Memory Scale-Revised; ROC, receiver operating characteristic; AUC, area under the curve.

\section{A Radial OF pattern produced} by forward self-movement

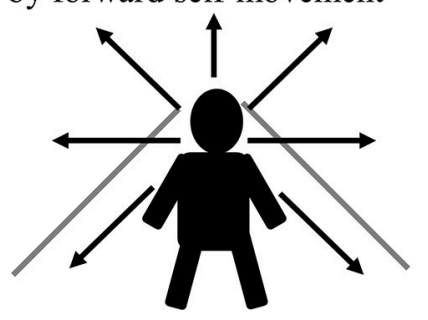

\section{B Coherent radial OF motion stimuli}

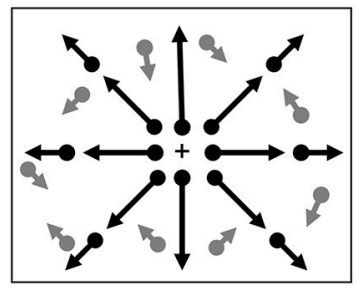

FIGURE 2 | Radial OF motion. (A) When we move through our environment, radial OF pattern is produced by forward self-movement. (B) Coherent radial OF motion stimuli used in our study. We can create radial OF motion stimuli easily using random dots. Dots radiate from the focus of expansion, which corresponds to the observer's direction of heading. OF, optic flow. 


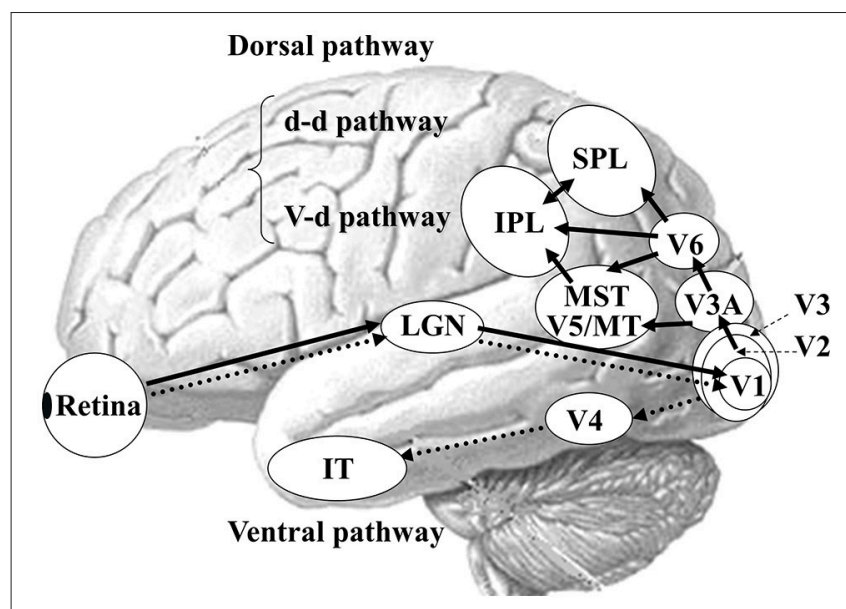

FIGURE 3 | Parallel visual pathways in humans. There are two major parallel streams: ventral and dorsal pathways in humans. Detailed functions of the two streams are provided in the text (see section Neural Basis of OF Perception in Healthy Humans). A recent study has revealed the importance of interconnection between IPL and SPL for OF processing (40) so that we modified this figure considering this point. $d$-d pathway, dorso-dorsal pathway; v-d pathway, ventro-dorsal pathway; LGN, lateral geniculate nucleus; MT, middle temporal area; MST, medial superior temporal area; IPL, inferior parietal lobule, SPL, superior parietal lobule; IT, inferior temporal cortex. [Modified from (41), Copyright (2012) with permission from IOS press].

stream is important for form and color perception, projecting to V4 and the inferior temporal (IT) cortex. In contrast, the dorsal stream is responsible for motion perception, connecting to $\mathrm{V} 5 /$ middle temporal $(\mathrm{MT})+(\mathrm{V} 5 / \mathrm{MT}$ and medial superior temporal area $[\mathrm{MST}]), \mathrm{V} 6$ and the posterior parietal cortex (21). The dorsal stream also comprises two distinct functional flows; the dorso-dorsal (d-d) and ventro-dorsal (v-d) streams (43). The d-d stream consists of V6 and the superior parietal lobule (SPL) while the $\mathrm{v}$-d stream involves V5/MT and the inferior parietal lobule (IPL). From the concept of such visual processing mechanism, the OF perception is mainly processed by the dorsal stream.

Primate studies have reported a number of cortical areas that selectively respond to OF, including the dorsal part of the MST (44), the ventral intraparietal area (VIP) (45), area $7 \mathrm{a}$ (46) as well as area PEc (47). Conversely, V5/MT neurons do not show such specific selectivity (48). In humans, several OF selective areas have been identified by neuroimaging studies within the dorsal streams (49-57). These OF selective areas contain visual areas such as MST and V6, multisensory areas such as the VIP, the precuneus motion area (PcM) and cingulate sulcus visual area, and vestibular areas such as the putative area $2 \mathrm{v}(\mathrm{p} 2 \mathrm{v})$ and parieto-insular vestibular cortex (PIVC). A recent fMRI study have demonstrated that the posterior-insular cortex (PIC) area plays an important role in the integration of visual and vestibular stimuli for the perception of self-motion while the PIVC is selectively responsive to vestibular stimulation $(58,59)$. Overall, the VIP, PcM and $\mathrm{p} 2 \mathrm{~V}$ are located within the $\mathrm{d}$-d stream (SPL) while the $\mathrm{v}$-d stream (IPL) consists of PIC (40).

\section{OF-ERPS IN HEALTHY HUMANS}

In order to compare OF processing with $\mathrm{HO}$ processing in healthy humans, we recorded ERPs for coherent OF and $\mathrm{HO}$ motion stimuli in healthy young subjects by using a highdensity EEG system (60) (Figures 2B, 4). We used coherent motion stimuli as the visual stimuli, which consisted of 400 white square dots randomly distributed on a black background. The white dots moved at a velocity of $5.0 \%$ s. Two types of motion stimuli (OF and $\mathrm{HO}$ ) were used. OF stimuli contained dots that moved in a radial outward pattern while $\mathrm{HO}$ contained dots that moved leftward or rightward. The coherent level was $90 \%$ in both stimuli. Both stimuli had the same dot density, luminance, contrast and average dot speed. Random motion (RM) was used as a baseline condition. The OF and HO stimuli were presented for $750 \mathrm{~ms}$, with the presentation of RM for 1,500-3,000 ms alternately. The N170 [analogous to N200 in previous ERP studies $(37,38$ ), about $170 \mathrm{~ms}$ ] and P200 (about $200 \mathrm{~ms}$ ) were recorded as major components. We analyzed the peak latencies, amplitudes, scalp distribution and the sources in both components.

The N170 was distributed over occipito-temporal regions in response to both $\mathrm{OF}$ and $\mathrm{HO}$ stimuli. The distribution of the OF-N170 extended further into the parietal region compared with those of HO-N170 (Figure 4B). The OF-N170 amplitude was significantly larger and its latency was significantly shorter than those of HO-N170 (Figure 4A). Exact low resolution brain electromagnetic tomography (eLORETA) analysis of the N170 revealed that the current density was significantly elevated over the occipito-temporal areas including V5/MT+ in response to both stimuli compared with RM baseline (Figure 5A). These findings were consistent with those of minimum-norm estimate (MNE) of visual evoked magnetic fields (VEFs) (61). A direct comparison between $\mathrm{OF}$ and $\mathrm{HO}$ stimuli revealed no significant difference in the current density of the N170. Current density estimation with eLORETA in ERPs and MNE in VEFs provided strong evidence that the generator source of the N170 was located in V5/MT+ for both stimuli. Therefore, the N170 constitutes a non-specific motion component derived from an area close to V5/MT+. However, OF stimuli elicited an N170 with a higher amplitude and shorter latency, compared with $\mathrm{HO}$ (Figure 4A), which may reflect a higher activity of V5/MT+ during OF processing. Alternatively, V5/MT + can be subdivided into V5/MT and MST $(50,62)$. V5/MT neurons respond to both $\mathrm{OF}$ and $\mathrm{HO}$ stimuli (48), whereas MST selectively responds to OF $(44,46)$. Thus, the selective activation of MST neurons may contribute to the higher amplitude and shorter latency of the OF-N170 response.

The P200 component exhibited distinct characteristics between OF and HO. The OF-P200 was distributed over the parieto-central region (Figure 4). HO stimulus also evoked an observable P200, but its topography was limited to the central region (Figure 4). The P200 amplitude was significantly larger for OF compared with $\mathrm{HO}$ stimuli. Similarly, the latency of OF-P200 was significantly faster compared with that of $\mathrm{HO}$ P200 (Figure 4A). Regarding the parietal OF-P200, the current density was significantly elevated in the IPL (Figure 5B, top 
A

B

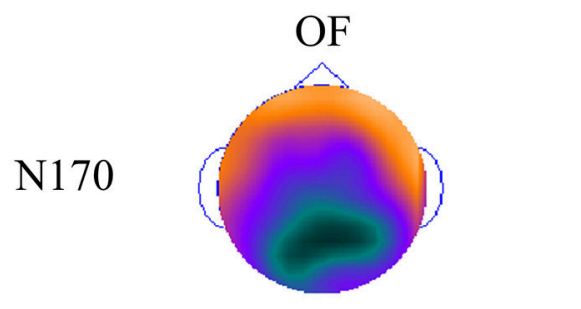

P200

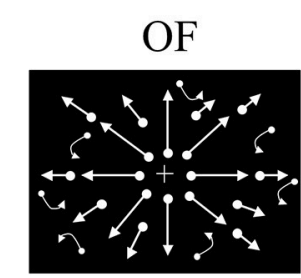

P3

P4

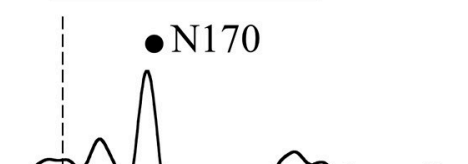

$\mathrm{Cz}$
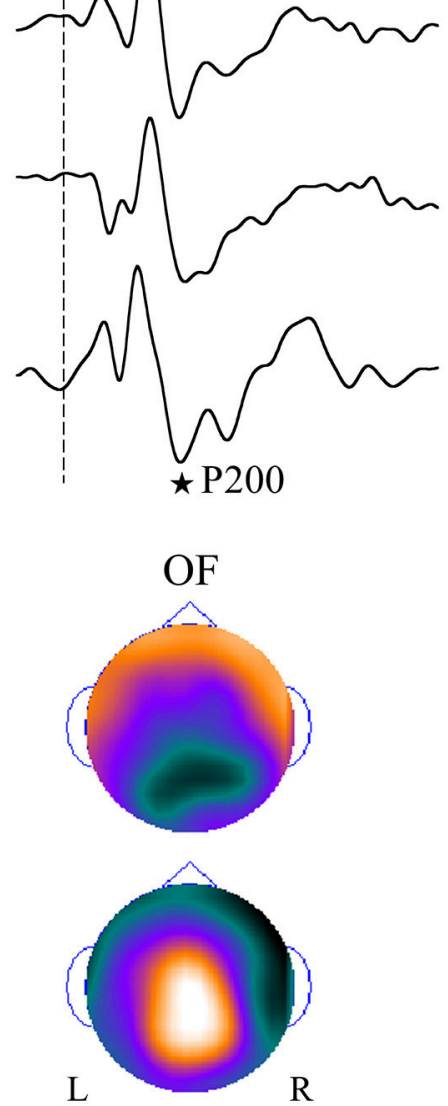

$\mathrm{HO}$
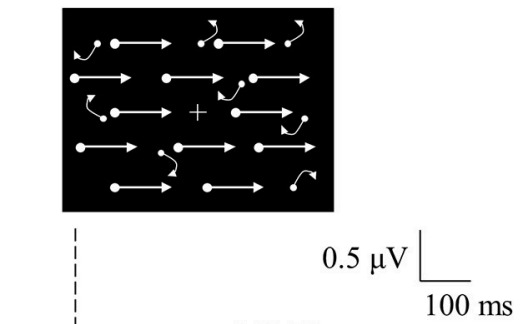

-N170

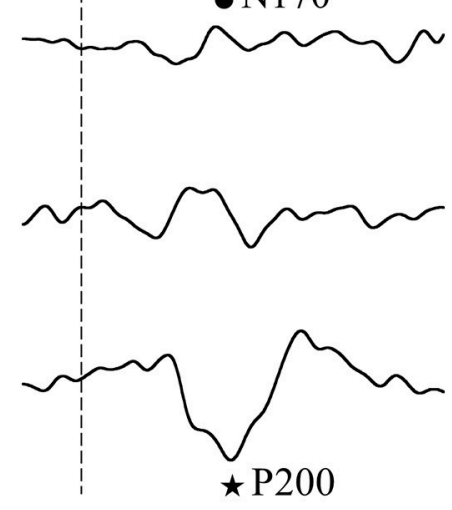

$\mathrm{HO}$

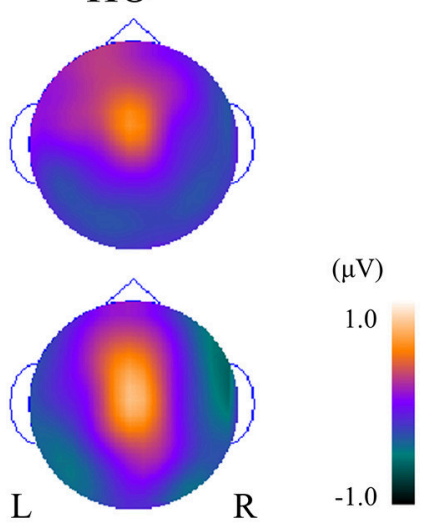

FIGURE 4 | ERPs in response to coherent OF and HO motion stimuli and their scalp topography in healthy subjects. (A) It is evident that the N170 and P200 are distinct motion-related components. The N170 component was distributed over occipito-temporal areas regardless of the stimulus type, extending further to the parietal region in the OF condition only. (B) The P200 component in response to OF stimuli was distributed over the parieto-central region while that of HO was distributed over the central region. The color bar represents the amplitude value (red = positive, blue = negative). Please note that this figure was presented at 2009 International Symposium on Early Detection and Rehabilitation Technology of Dementia. December 11-12, 2009, Okayama, Japan. ERPs, event-related potentials; HO, horizontal motion.

row). In contrast, for the central HO-P200, the current density was distributed over the SPL (Figure 5B, middle row). A direct comparison revealed that the current density of the IPL in response to OF stimuli compared with $\mathrm{HO}$ stimuli was significantly elevated (red color). Conversely, the current density of SPL was significantly elevated in $\mathrm{HO}$ compared with OF (blue color) (Figure 5B, bottom row). Overall, these findings suggest that the parietal OF-P200 is functionally coupled with the IPL (the v-d stream) and that it is the OF-specific component.
Conversely, the central HO-P200 is related to the SPL (the d$\mathrm{d}$ stream) (60). These functional dissociations between IPL (OF perception) and SPL (HO perception) were consistent with our fMRI study (41). Therefore, we propose that different spatiotemporal processing is driven by these motion stimuli within the two distinct dorsal streams in humans. From these findings, it is likely that ERPs with coherent OF and HO motion are useful for functional evaluation of the dorsal stream. More specifically, OF-related ERPs (OF-N170 and OF-P200 components) are 


\section{A $\quad \mathrm{N} 170$}
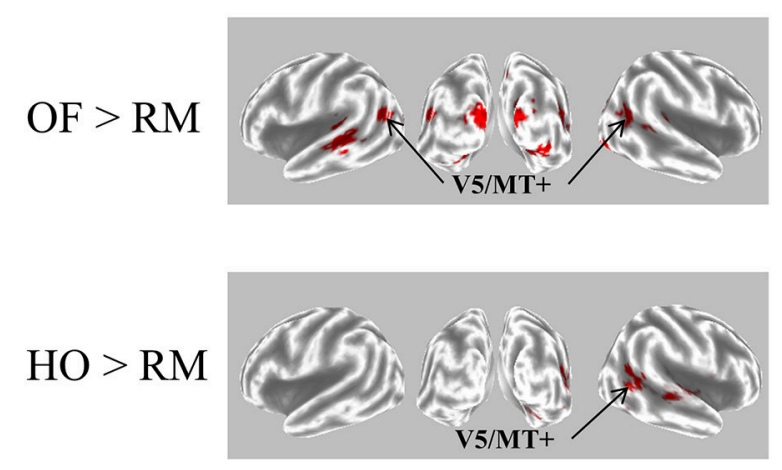

B $\quad$ P200
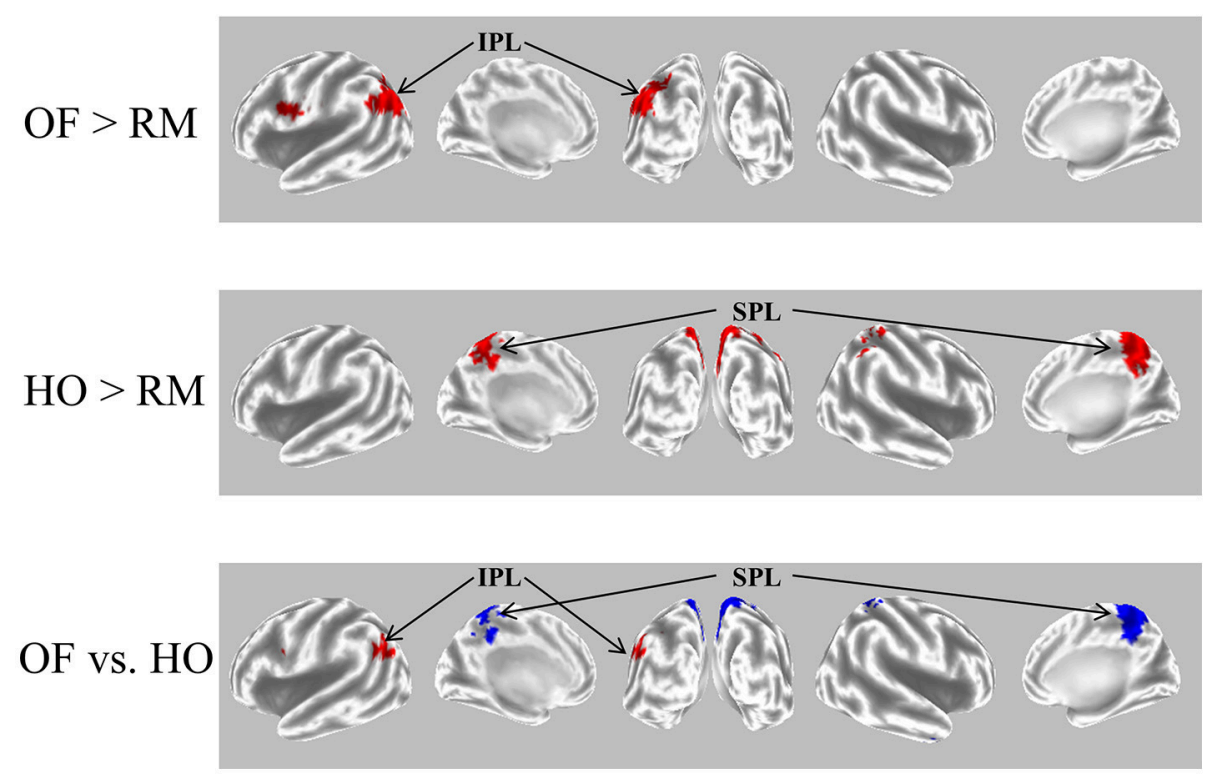

FIGURE 5 | eLORETA-based statistical nonparametric maps for a comparison between OF and HO in GFP peaks of N170 and P200. (A) The current density of N170 was significantly elevated over the occipito-temporal areas including V5/MT+ in both stimulus conditions. (B) The current density of the parietal P200 for OF was significantly elevated in the left IPL (BA 39/40). Conversely, there was a significant elevation of the current density of the central P200 for HO in the bilateral SPL (BA 7). In the figure at the bottom, red and blue mean OF and HO, respectively. Please note that this figure was presented at 2009 International Symposium on Early Detection and Rehabilitation Technology of Dementia. December 11-12, 2009, Okayama, Japan. eLORETA, exact low resolution brain electromagnetic tomography; GFP, global field power; RM, random motion.

considered to be able to identify subtle changes of visuospatial function (OF perception) associated with driving ability in individuals.

\section{OF-ERPS IN ADS}

To examine whether we can detect the impairment of $\mathrm{OF}$ perception in $\mathrm{aMCI}$ and $\mathrm{AD}$, ERPs for $\mathrm{OF}$ and $\mathrm{HO}$ were recorded in patients with aMCI and $\mathrm{AD}$, and in healthy old and young adults (1) (Table 2). aMCI was defined according to the criteria of Petersen (24). The patients with $\mathrm{AD}$ met the criteria for probable
AD according to NINCDS-ADRDA (63). Neuropsychological tests including MMSE and the Clinical Dementia Rating (CDR) were performed. Regarding ERPs, visual stimuli and analysis were same as the former study in healthy young subjects (60). There was no significant difference in both OF-N170 and HON170 responses between aMCI patients and healthy old adults (Figure 6). In contrast, the latency of OF-P200 was significantly prolonged in aMCI patients compared with healthy old adults (Figure 6). Therefore, within the dorsal stream, the v-d stream (IPL) related to OF perception, but not the d-d stream (SPL) associated with $\mathrm{HO}$ perception, is selectively impaired in aMCI 

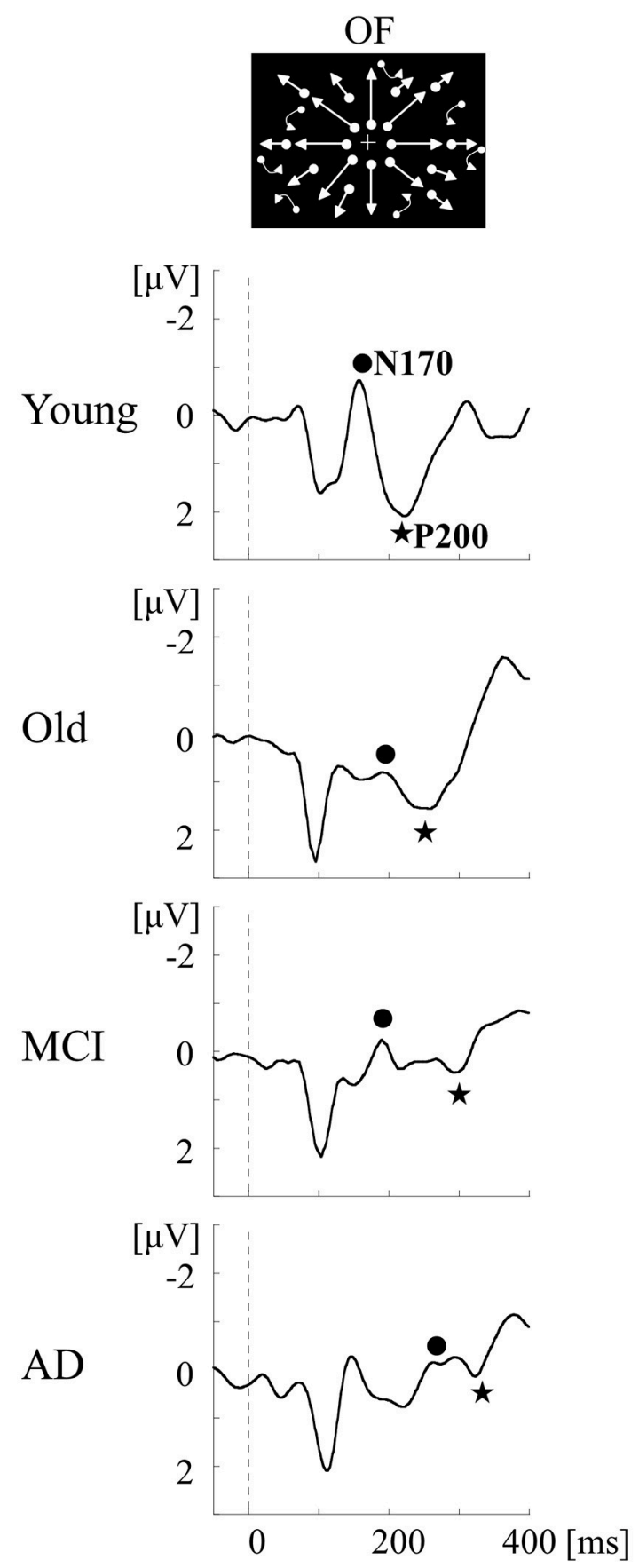
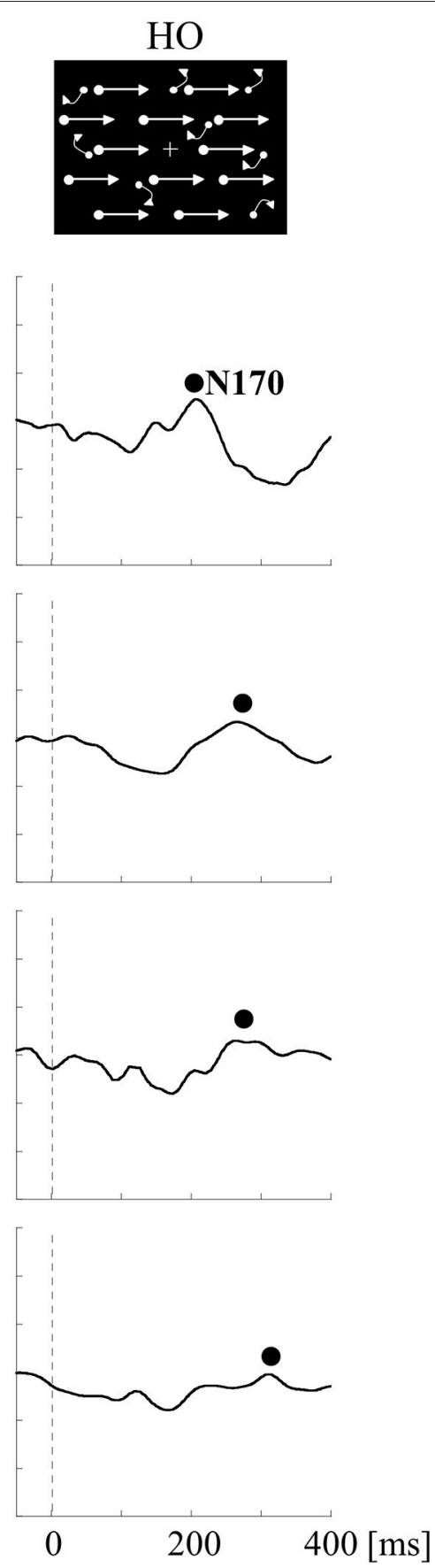

FIGURE 6 | ERPs in response to coherent OF and $\mathrm{HO}$ motion stimuli in the $\mathrm{MCl}, \mathrm{AD}$ and healthy control groups. MCI patients exhibit more prolongation of P200 latency for OF than healthy elderly adults, but no prolongation of N170 latency for both stimuli. AD patients show a prolongation of both N170 and P200 latencies compared with other groups. MCl, mild cognitive impairment. [Modified from (64), Copyright (2012) with permission from IEEE].

patients. On the other hand, $\mathrm{AD}$ patients showed a prolongation of N170 and P200 latencies for both OF and HO stimuli compared with healthy old adults and aMCI patients (Figure 6). Our results indicate that aMCI patients exhibit a selective impairment of OF perception related to the higher-level of dorsal stream ( $v$-d stream including IPL). Conversely, AD patients show the impairments of both OF and $\mathrm{HO}$ perception associated with the distributed higher-level dorsal stream (both $\mathrm{v}-\mathrm{d}$ and $\mathrm{d}$-d streams including IPL, SPL and V5/MT+). These findings were consistent with the spread of $\mathrm{AD}$ pathology following disease progression $(1,64)$. Thus, we can detect the impairment of OF perception even in patients with aMCI by using OF-ERPs. 
We further recorded ERPs to multimodal visual stimuli (chromatic and achromatic gratings, faces, kanji and kana words and OF motion) in aMCI patients, healthy old and young adults (2) (Table 2). Inclusion criteria for aMCI patients and healthy old adults followed the criteria of the Japanese Alzheimer's Disease Neuroimaging Initiative (65). These criteria were based on several neuropsychological tests: MMSE, CDR, Geriatric Depression Scale and the logical memory test (delayed recall) of the Wechsler Memory Scale-Revised (WMSR). Multimodal visual stimuli were optimized to activate elements of each visual stream separately. The OF stimulus was same as the former studies $(1,60)$. ERP responses to lower (V1) level stimuli (chromatic and achromatic gratings) were not significantly differed between aMCI patients and healthy old adults. Conversely, ERP latencies for higher-ventral (faces and kanji words) and higher-dorsal (kana words and OF motion) were significantly prolonged in aMCI patients. Interestingly, OF-related ERPs were significantly correlated with the logical memory test (delayed recall) of the WMS-R (OFN170 latency, $r=-0.507$; OF-P200 amplitude, $r=0.493$ ) (Figure 7A). Furthermore, the receiver operating characteristic (ROC) analysis exhibited that the highest area under the curve (AUC) was observed for OF-ERP latencies (OF-N170 latency, $\mathrm{AUC}=0.856 ;$ OF-P200 latency, $\mathrm{AUC}=0.831)($ Figure $7 \mathrm{~B})$.
This suggests that OF-ERPs have the best distinguishing ability between aMCI and healthy old adults.

\section{A POTENTIAL USE OF OPTIC FLOW-ERPS IN ASSESSING DRIVING ABILITY IN ADS}

Overall, in our ERP studies $(1,2)$, OF-related visuospatial perception indispensable for driving was associated with cognitive function in ADS. As previously mentioned, severity of decline in driving ability was correlated with the degree of cognitive function (23) or visuospatial function (17). Therefore, we assume that OF-ERPs can detect early signs of decline in driving ability in patients with ADS.

In support of our view that altered OF-related visuospatial perception is associated with the driving disability in ADS, Vilhelmsen et al. (66) found that the latency of N2 (analogous to N170 in our study) increased as the speed of OF-motion increased (driving speeds 25,50 , and $75 \mathrm{~km} / \mathrm{h}$ ) in healthy young subjects. They supposed that the subjects perceived the OF stimulus with higher speeds as more complex than that of the lower speeds, which resulted in the increased N2 latency. Healthy individuals can handle our OF stimulus easily but the damaged ADS brain may need more effort because of an excessive

\section{A OF motion: N170 latency}

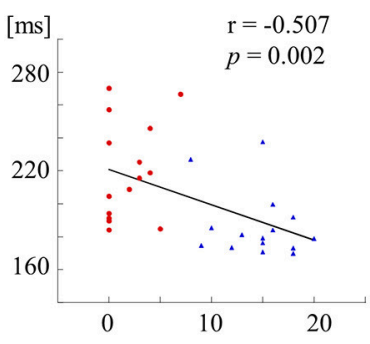

B OF motion: N170 latency

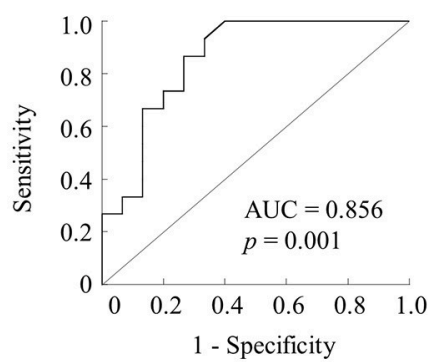

OF motion: P200 amplitude

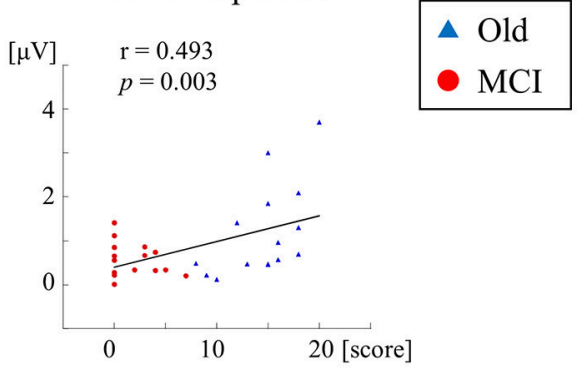

OF motion: P200 latency

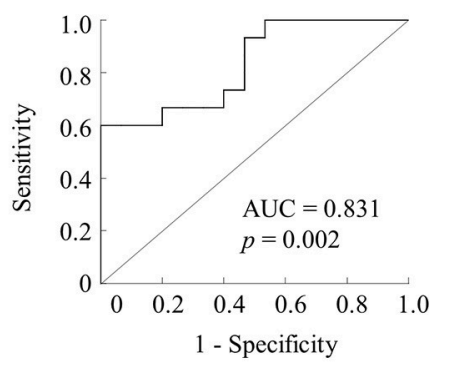

FIGURE 7 | Correlation and ROC analyses. (A) Correlation of ERPs with delayed LM WMS-R scores. ERPs for OF motion stimuli are significantly correlated with delayed LM WMS-R scores. (B) The results of ROC curve analysis for discriminability of ERP components. The N170 and P200 latencies for OF motion have AUCs $\geq$ the threshold of 0.7 for acceptable discrimination. Please note that AD group was not recruited in this study [Modified from (1), Copyright (2016) with permission from IOS press]. LM WMS-R, logical memory in Wechsler Memory Scale-Revised; ROC, receiver operating characteristic; AUC, area under the curve. 
load for the visuospatial processing system. This interpretation may explain the delayed N170 and P200 latencies in our study $(1,2)$.

Based on ERP findings of our $(1,2)$ and other groups $(37,38)$, OF-ERPs (both N170 and P200 components) may be useful for evaluation of driving ability in aMCI and AD patients. However, it should be kept in mind that the relationship between OFERPs and the performance of on-road and driving simulator tests has not established. In addition, we have not yet determined the reference values of OF-ERPs (amplitude and latency) on driving ability. Thus, in the near future, we will perform a largescale longitudinal ERP study for determining the relationship between driving ability and OF perception in a wide range of ADS. By doing so, we can assess driver's aptitude to prevent the traffic accidents in patients with ADS. Meanwhile, we are currently trying to develop the simple and reliable touch paneltype assessment system of driving ability using radial OF stimuli (measuring OF-detection threshold) (https://kaken.nii.ac.jp/en/ grant/KAKENHI-PROJECT-17K09801/). This system may be useful for driving performance evaluation, which is much simpler than ERPs.

\section{CONCLUSIONS}

To maintain safe driving, widespread brain networks including occipital, parietal, frontal, motor and cerebellar regions are recruited. These brain networks are vulnerable in ADS pathology that shows extensive neocortical brain damage. In ADS, the driving ability continues to gradually decline accompanied by the course of $\mathrm{AD}$ pathology. Especially, the early pathological change in the posterior temporo-parietal regions related to $\mathrm{OF}$

\section{REFERENCES}

1. Yamasaki T, Goto Y, Ohyagi Y, Monji A, Munetsuna S, Minohara M, et al. Selective impairment of optic flow perception in amnestic mild cognitive impairment: evidence from event-related potentials. J Alzheimers Dis. (2012) 28:695-708. doi: 10.3233/JAD-2011-110167

2. Yamasaki T, Horie S, Ohyagi Y, Tanaka E, Nakamura N, Goto Y, et al. A potential VEP biomarker for mild cognitive impairment: evidence from selective visual deficit of higher-level dorsal pathway. J Alzheimers Dis. (2016) 53:661-76. doi: 10.3233/JAD-150939

3. Hird MA, Egeto P, Fischer CE, Naglie G, Schweizer TA. A systematic review and meta-analysis of on-road simulator and cognitive driving assessment in Alzheimer's disease and mild cognitive impairment. J Alzheimers Dis. (2016) 53:713-29. doi: 10.3233/JAD-160276

4. Choi MH, Kim HS, Yoon HJ, Lee JC, Baek JH, Choi JS, et al. Increase in brain activation due to sub-tasks during driving: fMRI study using new MR-compatible driving simulator. J Physiol Anthropol. (2017) 36:11. doi: 10.1186/s40101-017-0128-8

5. Just MA, Keller TA, Cynkar J. A decrease in brain activation associated with driving when listening to someone speak. Brain Res. (2008) 1205:70-80. doi: 10.1016/j.brainres.2007.12.075

6. Schweizer TA, Kan K, Hung Y, Tam F, Naglie G, Graham SJ. Brain activity during driving with distraction: an immersive fMRI study. Front Hum Neurosci. (2013) 7:53. doi: 10.3389/fnhum.2013.00053

7. Spiers HJ, Maguire EA. Neural substrates of driving behaviour. Neuroimage (2007) 36:245-55. doi: 10.1016/j.neuroimage.2007. 02.032 perception is responsible for the impaired driving in the early stage of ADS. Although various methods including on-road test, driving simulation and neuropsychological tests are used for evaluating driving ability, there is no single test sufficient to determine driving safety in ADS patients. Conversely, ERPs are non-invasive and objective method that can be performed easily, in a short time, at a low cost, but has high reliability. Based on previous and our ERP studies, OF-ERPs can be an indicative neural biomarker for assessing the decline of driving ability in ADS.

\section{AUTHOR CONTRIBUTIONS}

All authors listed have made a substantial, direct and intellectual contribution to the work, and approved it for publication.

\section{FUNDING}

This study was partly supported by the following grants: JSPS KAKENHI Grant Number JP17K09801 to TY, and Grant from the Research on Innovative Areas (No.15H05875) from the Ministry of Education, Culture, Sports, Science, and Technology to ST.

\section{ACKNOWLEDGMENTS}

We wish to thank Drs. Yasumasa Ohyagi (Department of Neurology and Geriatric Medicine, Ehime University), Junichi Kira (Department of Neurology, Kyushu University) and Shigenobu Kanba (Department of Neuropsychiatry, Kyushu University) for their research assistance.

8. Uchiyama Y, Ebe K, Kozato A, Okada T, Sadato N. The neural substrates of driving at a safe distance: a functional MRI study. Neurosci Lett. (2003) 352:199-202. doi: 10.1016/j.neulet.2003.08.072

9. Allison S, Babulal GM, Stout SH, Barco PP, Carr DB, Fagan AM, et al. Alzheimer disease biomarkers and driving in clinically normal older adults: role of spatial navigation abilities. Alzheimer Dis Assoc Disord. (2018) 32:1016. doi: 10.1097/WAD.0000000000000257

10. Hird MA, Vesely KA, Fischer CE, Graham SJ, Naglie G, Schweizer TA. Investigating simulated driving errors in amnestic single- and multipledomain mild cognitive impairment. J Alzheimers Dis. (2017) 56:447-52. doi: 10.3233/JAD-160995

11. Roe CM, Babulal GM, Mishra S, Gordon BA, Stout SH, Ott BR, et al. Tau and amyloid positron emission tomography imaging predict driving performance among older adults with and without preclinical Alzheimer's disease. J Alzheimers Dis. (2018) 61:509-13. doi: 10.3233/JAD-170521

12. Alzheimer's Association. 2018 Alzheimer's disease facts and figures. Alzheimers Dement. (2018) 14:367-429. doi: 10.1016/j.jalz.2018.02.001

13. Petersen RC. New clinical criteria for the Alzheimer's disease spectrum. Minn Med. (2012) 95:42-5.

14. Sperling RA, Aisen PS, Beckett LA, Bennett DA, Craft S, Fagan AM, et al. Toward defining the preclinical stages of Alzheimer's disease: recommendations from the National Institute on Aging-Alzheimer's Association workgroups on diagnostic guidelines for Alzheimer's disease. Alzheimers Dement. (2011) 7:280-92. doi: 10.1016/j.jalz.2011.03.003

15. Albert MS, DeKosky ST, Dickson D, Dubois B, Feldman HH, Fox NC, et al. The diagnosis of mild cognitive impairment due to Alzheimer's disease: recommendations from the National Institute on Aging-Alzheimer's 
Association workgroups on diagnostic guidelines for Alzheimer's disease. Alzheimers Dement. (2011) 7:270-9. doi: 10.1016/j.jalz.2011.03.008

16. McKhann GM, Knopman DS, Chertkow H, Hyman BT, Jack CRJr, Kawas CH, et al. The diagnosis of dementia due to Alzheimer's disease: recommendations from the national institute on aging-alzheimer's association workgroups on diagnostic guidelines for alzheimer's disease. Alzheimers Dement. (2011) 7:263-9. doi: 10.1016/j.jalz.2011.03.005

17. Bennett JM, Chekaluk HE, Batchelor J. Cognitive tests and determining fitness to drive in dementia: a systematic review. J Am Geriatr Soc. (2016) 64:1904-17. doi: 10.1111 /jgs. 14180

18. Mapstone M, Steffenella TM, Duffy CJ. A visuospatial variant of mild cognitive impairment: getting lost between aging and AD. Neurology (2003) 60:802-8. doi: 10.1212/01.WNL.0000049471.76799.DE

19. Tetewsky SJ, Duffy CJ. Visual loss and getting lost in Alzheimer's disease. Neurology (1999) 52:958-65.

20. Gibson JJ. The Perception of the Visual World. Boston, MA: Houghton Mifflin (1950).

21. Tobimatsu S, Celesia GG. Studies of human visual pathophysiology with visual evoked potentials. Clin Neurophysiol. (2006) 117:1414-33. doi: 10.1016/j.clinph.2006.01.004

22. Yamasaki T, Tobimatsu S. Electrophysiological assessment of the human visual system. In: Harris JM, Scott J, editors. Neuroscience Research Progress, Visual Cortex: Anatomy, Functions and Injuries. New York, NY: Nova Science Publishers (2012). p. 37-67.

23. Ott BR, Heindel WC, Papandonatos GD, Festa EK, Davis JD, Daiello LA, et al. A longitudinal study of drivers with Alzheimer disease. Neurology (2008) 70:1171-8. doi: 10.1212/01.wnl.0000294469.27156.30

24. Petersen RC. Mild cognitive impairment as a diagnostic entity. J Intern Med. (2004) 256:183-94. doi: 10.1111/j.1365-2796.2004.01388.x

25. Ott BR, Heindel WC, Whelihan WM, Caron MD, Piatt AL, Noto RB. A singlephoton emission computed tomography imaging study of driving impairment in patients with Alzheimer's disease. Dement Geriatr Cogn Disord. (2000) 11:153-60. doi: 10.1159/000017229

26. Matías-Guiu JA, Cabrera-Martín MN, Valles-Salgado M, Pérez-Pérez A, Rognoni T, Matías-Guiu J, et al. Neural basis of cognitive assessment in Alzheimer disease, amnestic mild cognitive impairment, and subjective memory complaints. Am J Geriatr Psychiatry (2017) 25:730-40. doi: 10.1016/j.jagp.2017.02.002

27. Braak H, Braak E. Neuropathological stageing of Alzheimer-related changes. Acta Neuropathol. (1991) 82:239-59. doi: 10.1007/BF00308809

28. Ott BR, Jones RN, Noto RB, Yoo DC, Snyder PJ, Bernier JN, et al. Brain amyloid in preclinical Alzheimer's disease is associated with increased driving risk. Alzheimers Dement. (2017) 6:136-42. doi: 10.1016/j.dadm.2016.10.008

29. Piersma D, Fuermaier AB, de Waard D, Davidse RJ, de Groot J, Doumen MJ, et al. Prediction of fitness to drive in patients with Alzheimer's dementia. PLoS ONE (2016) 11:e0149566. doi: 10.1371/journal.pone.0149566

30. Horváth A, Szucs A, Csukly G, Sákovics A, Stefanics G, Kamondi A. EEG and ERP biomarkers of Alzheimer's disease: a critical review. Front Biosci. (2018) 23:183-220. doi: 10.2741/4587

31. Scally B, Calderon PL, Anghinah R, Parra MA. Event-related potentials in the continuum of Alzheimer's disease: would they suit recent guidelines for preclinical assessment? J Clin Diagn Res. (2016) 4:127. doi: 10.4172/2376-0311.1000127

32. Olichney JM, Yang JC, Taylor J, Kutas M. Cognitive event-related potentials: biomarkers of synaptic dysfunction across the stages of Alzheimer's disease. $J$ Alzheimers Dis. (2011) 26:215-28. doi: 10.3233/JAD-2011-0047

33. Ou B, Wu C, Zhao G, Wu J. P300 amplitude reflects individual differences of navigation performance in a driving task. Int J Ind Ergon. (2012) 42:8-16. doi: 10.1016/j.ergon.2011.11.006

34. Ebe K, Itoh K, Kwee IL, Nakada T. Covert effects of "one drink" of alcohol on brain processes related to car driving: an event-related potential study. Neurosci Lett. (2015) 593:78-82. doi: 10.1016/j.neulet.2015. 03.020

35. Chai J, Qu W, Sun X, Zhang K, Ge Y. Negativity bias in dangerous drivers. PLoS ONE (2016) 11:e0147083. doi: 10.1371/journal.pone. 0147083

36. Solís-Marcos I, Galvao-Carmona A, Kircher K. Reduced attention allocation during short periods of partially automated driving: an event-related potentials study. Front Hum Neurosci. (2017) 11:537. doi: 10.3389/fnhum.2017.00537

37. Fernandez R, Duffy CJ. Early Alzheimer's disease blocks responses to accelerating self-movement. Neurobiol Aging (2012) 33:2551-60. doi: 10.1016/j.neurobiolaging.2011.12.031

38. Fernandez-Romero R, Cox DJ. Impaired driving capacity in early stage Alzheimer's is associated with decreased cortical responsiveness to simulated self-movement. Alzheimers Dement. (2016) 12:882. doi: 10.1016/j.jalz.2016.06.1824

39. Warren WH, Hannon DJ. Direction of self-motion is perceived from optic flow. Nature (1988) 336:162-3. doi: 10.1038/336162a0

40. Uesaki M, Takemura H, Ashida H. Computational neuroanatomy of human stratum proprium of interparietal sulcus. Brain Struct Funct. (2018) 223:489507. doi: 10.1007/s00429-017-1492-1

41. Yamasaki T, Horie S, Muranaka H, Kaseda Y, Mimori Y, Tobimatsu S. Relevance of in vivo neurophysiological biomarkers for mild cognitive impairment and Alzheimer's disease. J Alzheimers Dis. (2012) 31:S137-54. doi: 10.3233/JAD-2012-112093

42. Livingstone M, Hubel D. Segregation of form, color, movement, and depth: anatomy, physiology, and perception. Science (1988) 240:740-9. doi: $10.1126 /$ science. 3283936

43. Rizzolatti G, Matelli M. Two different streams form the dorsal visual system: anatomy and functions. Exp Brain Res. (2003) 153:146-57. doi: $10.1007 / \mathrm{s} 00221-003-1588-0$

44. Tanaka K, Saito H. Analysis of motion of the visual field by direction, expansion/contraction and rotation cells in the dorsal part of the medial superior temporal area of the macaque monkey. J Neurophysiol. (1989) 62:642-56. doi: $10.1152 /$ jn.1989.62.3.642

45. Zhang T, Heuer HW, Britten KH. Parietal area VIP neuronal responses to heading stimuli are encoded in head-centered coordinates. Neuron (2004) 42:993-1001. doi: 10.1016/j.neuron.2004.06.008

46. Siegel RM, Reid HL. Analysis of optic flow in the monkey parietal 7a. Cereb Cortex (1997) 7:327-46. doi: 10.1093/cercor/7.4.327

47. Raffi M, Squatrito S, Maioli MG. Neuronal responses to optic flow in the monkey parietal area PEc. Cereb Cortex (2002) 12:639-46. doi: $10.1093 /$ cercor/12.6.639

48. Lagae L, Maes H, Raiguel S, Xiao DK, Orban GA. Responses of macaque STS neurons to optic flow components: a comparison of MT and MST. J Neurophysiol. (1994) 71:1597-626. doi: 10.1152/jn.1994.71. 5.1597

49. de Jong BM, Shipp S, Skidmore B, Frackowiak RS, Zeki S. The cerebral activity related to the visual perception of forward motion in depth. Brain (1994) 117:1039-54. doi: 10.1093/brain/117.5.1039

50. Morrone MC, Tosetti M, Montanaro D, Fiorentini A, Cioni G, Burr DC. A cortical area that responds specifically to optic flow, revealed by fMRI. Nat Neurosci. (2000) 12:1322-8. doi: 10.1038/81860

51. Peuskens H, Sunaert S, Dupont P, Van Hecke P, Orban GA. Human brain regions involved in heading estimation. J Neurosci. (2001) 21:2451-61. doi: 10.1523/JNEUROSCI.21-07-02451.2001

52. Ptito M, Kupers R, Faubert J, Gjedde A. Cortical representation of inward and outward radial motion in man. Neuroimage (2001) 14:1409-15. doi: 10.1006/nimg.2001.0947

53. Wunderlich G, Marshall JC, Amunts K, Weiss PH, Mohlberg H, Zafieris O, et al. The importance of seeing it coming: a functional magnetic resonance imaging study of motion-in-depth towards the human observer. Neuroscience (2002) 112:535-40. doi: 10.1016/S0306-4522(02)00110-0

54. Cardin V, Smith AT. Sensitivity of human visual and vestibular cortical regions to egomotion-compatible visual stimulation. Cereb Cortex (2010) 20:1964-73. doi: 10.1093/cercor/bhp268

55. Biagi L, Crespi SA, Tosetti M, Morrone MC. BOLD response selective to flow-motion in very young infants. PLoS Biol. (2015) 13:e1002260. doi: 10.1371/journal.pbio.1002260

56. Uesaki M, Ashida H. Optic-flow selective cortical sensory regions associated with self-reported states of vection. Front Psychol. (2015) 6:775. doi: 10.3389/fpsyg.2015.00775

57. Wada A, Sakano Y, Ando H. Differential responses to a visual self-motion signal in human medial cortical regions revealed by wide-view stimulation. Front Psychol. (2016) 7:309. doi: 10.3389/fpsyg.2016.00309 
58. Frank SM, Baumann O, Mattingley JB, Greenlee MW. Vestibular and visual responses in human posterior insular cortex. J Neurophysiol. (2014) 112:248191. doi: $10.1152 /$ jn. 00078.2014

59. Frank SM, Wirth AM, Greenlee MW. Visual-vestibular processing in the human Sylvian fissure. J Neurophysiol. (2016) 116:263-71. doi: 10.1152 /jn.00009.2016

60. Yamasaki T, Tobimatsu S. Motion perception in healthy humans and cognitive disorders. In: Wu J, editor. Early Detection and Rehabilitation Technologies for Dementia: Neuroscience and Biomedical Applications. Hershey, PA: IGI Global (2011).p. 156-61.

61. Yamasaki T, Inamizu S, Goto Y, Tobimatsu S. Visual system: clinical applications. In: Tobimatsu S, Kakigi R, editors. Clinical Applications of Magnetoencephalography. Tokyo: Springer Japan KK (2016). p. 145-59.

62. Huk AC, Dougherty RF, Heeger DJ. Retinotopy and functional subdivision of human area MT and MST. J Neurosci. (2002) 22:7195-205. doi: 10.1523/JNEUROSCI.22-16-07195.2002

63. McKhann G, Drachman D, Folstein M, Katzman R, Price D, Stadlan EM. Clinical diagnosis of alzheimer's disease: report of the NINCDS-ADRDA work group under the auspices of department of health and human services task force on Alzheimer's disease. Neurology (1984) 34:939-44.

64. Yamasaki T, Goto Y, Ohyagi Y, Monji A, Munetsuna S, Minohara M, et al. A deficit of dorsal stream function in patients with mild cognitive impairment and Alzheimer's disease. In: 2012 IEEE/ICME International Conference on Complex Medical Engineering (Kobe) (2012). p. 28-31.
65. Ikari Y, Nishio T, Makishi Y, Miya Y, Ito K, Koeppe RA, et al. Head motion evaluation and correlation for PET scans with 18F-FDG in the Japanese Alzheimer's disease neuroimaging initiative (J-ADNI) multicenter study. Ann Nucl Med. (2012) 26:535-44. doi: 10.1007/s12149-0120605-4

66. Vilhelmsen K, van der Weel FR, van der Meer ALH. A highdensity EEG study of differences between three high speeds of simulated forward motion from optic flow in adult participants. Front Syst Neurosci. (2015) 9:146. doi: 10.3389/fnsys.2015. 00146

Conflict of Interest Statement: The authors declare that the research was conducted in the absence of any commercial or financial relationships that could be construed as a potential conflict of interest.

The reviewer DS and handling editor declared their shared affiliation.

Copyright (c) 2018 Yamasaki and Tobimatsu. This is an open-access article distributed under the terms of the Creative Commons Attribution License (CC BY). The use, distribution or reproduction in other forums is permitted, provided the original author(s) and the copyright owner(s) are credited and that the original publication in this journal is cited, in accordance with accepted academic practice. No use, distribution or reproduction is permitted which does not comply with these terms. 